\title{
Semi-Nested Real-Time Reverse Transcription Polymerase Chain Reaction Methods for the Successful Quantitation of Cytokeratin mRNA Expression Levels for the Subtyping of Non-Small-Cell Lung Carcinoma Using Paraffin-Embedded and Microdissected Lung Biopsy Specimens
}

\author{
Yoko Nakanishi ${ }^{1}$, Tetsuo Shimizu², Ichiro Tsujino², Yukari Obana ${ }^{1}$, Toshimi Seki ${ }^{3}$, \\ Fumi Fuchinoue ${ }^{1}$, Sumie Ohni ${ }^{1}$, Toshinori Oinuma ${ }^{4}$, Yoshiaki Kusumi ${ }^{1}$, \\ Tsutomu Yamada ${ }^{1}$, Noriaki Takahashi², Shu Hashimoto ${ }^{2}$ and Norimichi Nemoto ${ }^{1}$ \\ ${ }^{1}$ Department of Pathology, Nihon University School of Medicine, Tokyo, Japan, ${ }^{2}$ Department of Respiratory Medicine, Nihon \\ University School of Medicine, Tokyo, Japan, ${ }^{3}$ Pathology Laboratory, Nihon University Itabashi Hospital and ${ }^{4}$ Department \\ of Pathology, Kawaguchi Municipal Medical Center, Saitama, Japan
}

Received June 26, 2012; accepted March 19, 2013; published online April 12, 2013

\begin{abstract}
In patients with inoperable advanced non-small cell lung carcinomas (NSCLCs), histological subtyping using small-mount biopsy specimens was often required to decide the indications for drug treatment. The aim of this study was to assess the utility of highly sensitive mRNA quantitation for the subtyping of advanced NSCLC using small formalin fixing and paraffin embedding (FFPE) biopsy samples. Cytokeratin (CK) 6, CK7, CK14, CK18, and thyroid transcription factor (TTF)-1 mRNA expression levels were measured using semi-nested real-time quantitative (snq) reverse-transcribed polymerase chain reaction (RT-PCR) in microdissected tumor cells collected from 52 lung biopsies. Our results using the present snqRT-PCR method showed an improvement in mRNA quantitation from small FFPE samples, and the mRNA expression level using snqRT-PCR was correlated with the immunohistochemical protein expression level. CK7, CK18, and TTF-1 mRNA were expressed at significantly higher levels $(P<0.05)$ in adenocarcinoma $(A D)$ than in squamous cell carcinoma (SQ), while CK6 and CK14 mRNA expression was significantly higher $(P<0.05)$ in $S Q$ than in $A D$. Each histology-specific CK, particularly CK18 in $A D$ and CK6 in $S Q$, were shown to be correlated with a poor prognosis $(P=0.02,0.02$, respectively). Our results demonstrated that a quantitative CK subtype mRNA analysis from lung biopsy samples can be useful for predicting the histology subtype and prognosis of advanced NSCLC.
\end{abstract}

Key words: NSCLC, subtyping, laser microdissection, quantitative (q) RT-PCR, cytokeratin

\section{Introduction}

The histological subtyping of non-small cell lung carcinoma (NSCLC) has recently been recognized for its clinical and therapeutic importance [18]. Relevant distinctions that determine treatment choice have been made

Correspondence to: Yoko Nakanishi, Department of Pathology, Nihon University School of Medicine, 30-1 Ohyaguchi-kamimachi, Itabashi-ku, Tokyo 173-8610, Japan.

E-mail: nakanishi.youko@nihon-u.ac.jp between adenocarcinoma (AD) and squamous cell carcinoma (SQ) in NSCLC $[18,28]$. The emergence of treatments with differential activities or limited indications in the subtypes of NSCLC has placed further emphasis on the importance of accurate subtyping $[3,4,8,18,22,28$, $35,36]$, and immunohistochemical panels have been reported to be useful for subtyping $[5,22,35]$. In NSCLC, positive immunohistochemical staining for CK7, thyroid transforming factor (TTF)-1, and Napsin A have been reported for ADs, while positive staining for CK5/6 and CK14 have been reported for SQs [22, 35]. 
Cytokeratins (CK), the typical intermediate filament proteins of epithelia, show an outstanding degree of molecular diversity [5, 21]. In humans, 54 functional keratin genes exist and are expressed in specific patterns related to the epithelial type and the cellular differentiation. These proteins have been suggested to play a functional role via cell-cell contacts $[11,37]$. In tumor diagnosis, in particular, the immunohistochemical expressions of CK5, CK7, CK8/18, CK19, and CK20 have great importance in the precise classification, subtyping, and detection of unclear metastasis [5]. In many cases, NSCLC subtyping can be performed through pathological and immunohistochemical examinations if lung surgical resections are available. In the case of advanced lung cancer without any indications for surgery, lung biopsy specimens are important for confirming the presence of tumor cells. Transbronchial lung biopsy (TBLB) specimens are sometimes too small to make pathomorphological evaluations because sufficient tissue sections for the various immunostainings are not available. Furthermore, biopsy specimens are typically fixed with formalin and embedded in paraffin (FFPE). FFPE tissue specimens are thought to be unsuitable for genetic examination after long periods of time have elapsed. However, molecular biological technologies for examining archival FFPE samples are now more developed $[2,9,10,12,14$, $29,32,34]$. The possibility of measuring mRNA levels in FFPE tissue specimens has been reported, despite RNA fragmentation [6, 9, 10, 27, 29, 31, 34]. We also previously reported the performance of genetic analyses on various microdissected clinical samples, including FFPE tissues $[15,20,23-25]$. In the field of microbiology, as more sensitive PCR methods, nested PCR and semi-nested (sn) PCR techniques have been reported to be useful for detecting microbial DNA from human plasma and blood cultures [26, 30]. Nested PCR and SnPCR are techniques in which an additional amplification is added to the conventional (first) PCR, and the number of primers for total PCR amplification differs. Conventional PCR requires primers complementary to the termini of the target DNA (Fig. 1A). Nested PCR involves two sets of primers, used in two successive runs of PCR, with the second set intended to amplify a secondary target within the first run product (Fig. 1B). The primers used in the first round of amplification are either both replaced (nested PCR) or only one or none are replaced (semi-nested PCR, Fig. 1C, D) for the second and subsequent cycles of amplification. Eventually, the sensitivity of the PCR increases.

Although nested PCR methods need a total of four primers (Fig. 1B) and SnPCR methods often use a total of three primers in two PCR runs (Fig. 1C), we studied a method based on snRT-PCR using a total of two primers (Fig. 1D). Because of the fragmentation of RNA extracted from small-mount FFPE samples, the size of the RT-PCR product should be selected so as to be smaller than the conventional RT-PCR, and the inset primers for the second PCR reaction are sometimes difficult to select. If different sets of primers are used in two PCR runs, each melting temperature will differ and the amplification parameters

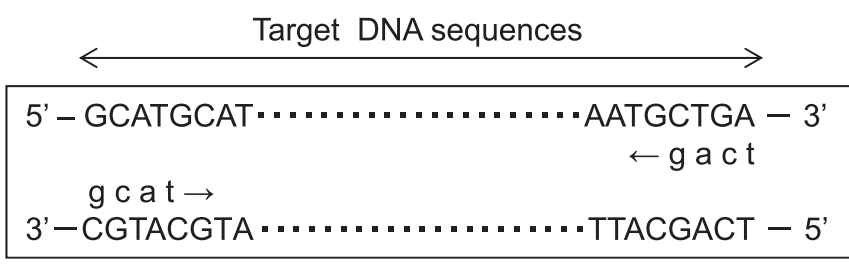

$$
\begin{aligned}
& \text { 5' - GCATGCAT } \ldots \ldots \ldots \ldots \ldots \ldots \ldots \text { AATGCTGA - } 3 \text { ' } \\
& \text { g c at } \rightarrow \\
& 3^{\prime}-\text { CGTACGTA } \cdots \ldots \ldots \ldots \ldots \ldots \text { TTACGACT }-5
\end{aligned}
$$

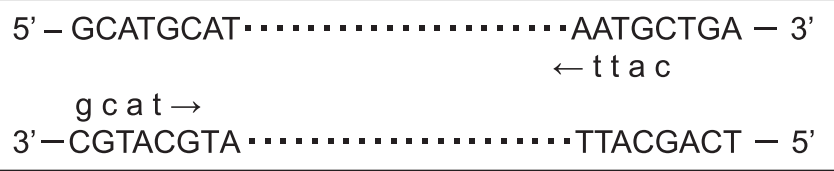

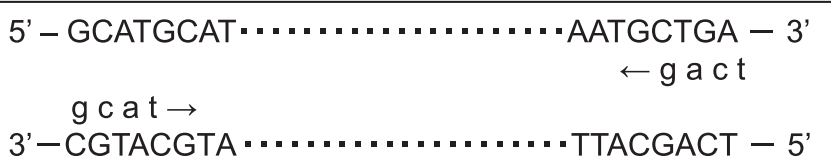

\section{A: Primers for the first PCR}

(2 primers are required.)

\section{B: Primers for nested PCR}

( Total 4 primers are required for the first and the second PCR reaction.)

The second PCR products is shorter than the first.

\section{C: Primers for semi-nested PCR}

( Total 3 primers are required for the first and the second PCR reaction.)

The second PCR products is shorter than the first.

\section{D: Primers for the present semi-nested PCR}

( The same 2 primers for the first PCR reaction are used for the second PCR reaction.)

The second PCR products is same length as the first.

Fig. 1. Differences of primers for various second PCR runs are shown. After nested PCR $(\mathbf{B})$ and semi-nested PCR $(\mathbf{C})$ reactions, PCR products are shorter than the first target DNA sequences. 
will need to be changed. Recently, selection methods for highly specific primers against target DNA have been simplified, thanks to computer technology. In this study, we analyzed the kinds of cytokeratin (CK) and TTF-1, which are well-known immunohistochemical markers for NSCLC subtyping, in small-mount FFPE lung biopsy specimens using laser-assisted microdissection (LMD) and semi-nested real-time quantitative (snq) RT-PCR.

\section{Materials and Methods}

\section{Samples}

Fifty-two FFPE lung biopsy tissue blocks were obtained from 47 lung cancer and 5 malignancy-free patients before the initiation of treatment at Nihon University Itabashi Hospital (Tokyo, Japan) between 2004 and 2009. This method was approved by the institutional ethical review board. The histological subtypes of lung cancer as determined by a pathological diagnosis were as follows: 25 adenocarcinomas (AD), 13 squamous cell carcinomas (SQ), and 9 small cell carcinomas (SM). A summary of the cases is shown in Table 1.

\section{Laser microdissection}

Eight-micrometer-thick sections were sliced from the paraffin blocks and mounted onto glass slides with a specific membrane film for laser microdissection. After deparaffinization, sections were stained with toluidine blue and dried at room temperature. The target tumor cells were dissected and collected (Fig. 2) using PALM ${ }^{\circledR}$ MicroBeam III-N (Carl Zeiss Microscopy, Munich, Germany). Airway epithelial cells and tracheal gland cells were dissected and collected from non-neoplastic tissues as a control. In total,

Table 1. Summary of the patients

\begin{tabular}{lc} 
Carcinoma samples & \\
Age (years) & $67.5 \pm 9.3$ \\
male:female (n) & $31: 16$ \\
Histology (n) & \\
adenocarcinoma & 25 \\
squamous cell carcinoma & 13 \\
small cell carcinoma & 9 \\
Stage (n) & \\
I & 4 \\
II & 4 \\
IIIA & 7 \\
IIIB & 21 \\
IV & 11 \\
Prognosis (n) & \\
alive & 20 \\
death & 22 \\
no information & 5 \\
Non-neoplastic samples & 5 \\
Age (years) & $69.2 \pm 9.5$ \\
Total (n) & 52 \\
\hline
\end{tabular}

10-100 cells were collected. The details of the LMD procedure have been previously described [26].

\section{Total RNA extraction}

The sample of target tumor cells was mixed with $200 \mu \mathrm{L}$ of denaturing buffer containing $2 \%$ SDS, $0.1 \mathrm{mM}$ EDTA, and $10 \mathrm{mM}$ Tris- $\mathrm{HCl}$, and incubated at $55^{\circ} \mathrm{C}$ with proteinase $\mathrm{K}$ until the sections dissolved completely. Total RNA was purified with $20 \mu \mathrm{L}$ of $2 \mathrm{M}$ sodium acetate $(\mathrm{pH}$

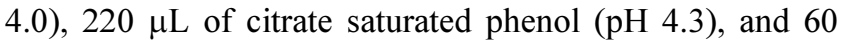
$\mu \mathrm{L}$ of chloroform-isoamyl alcohol. Following centrifugation for $15 \mathrm{~min}$ at $15,000 \mathrm{rpm}$, the upper aqueous layer was transferred into fresh tubes, and $200 \mu \mathrm{L}$ of isopropanol and $2 \mu \mathrm{L}$ of glycogen as a carrier were added. Samples were then frozen at $-80^{\circ} \mathrm{C}$ for more than $30 \mathrm{~min}$ before the pellets were collected by centrifugation for 30 min at $14,000 \mathrm{rpm}$, washed with $70 \%$ ethanol, and air-dried on ice. The pellets were subsequently dissolved in 5-10 $\mu \mathrm{L}$ RNase-free water and were quantified at an optical density of $260 \mathrm{~nm}$ using a Nanodrop 1000 spectrophotometer (Thermo Fisher Scientific Inc., Wilmington, DE, U.S.A.). The total RNA samples were stored at $-80^{\circ} \mathrm{C}$ until use. Both genomic DNA elimination and cDNA synthesis were performed using the Quantitect Reverse Transcription Kit (QIAGEN, Tokyo, Japan), according to the manufacture's instructions.

\section{Semi-nested real-time RT-PCR assays}

The mRNA expression level of CK6, CK7, CK14, CK18, TTF-1, and the internal control GAPDH were measured using the snqRT-PCR method. The first RTPCR reaction was carried out with each target and control cDNA by using the AmpliTaq Gold ${ }^{\circledR} 360$ Master Mix (Life Technologies Japan, Tokyo, Japan) and the respective primers shown in Table 2. Samples were incubated at $95^{\circ} \mathrm{C}$ for $10 \mathrm{~min}$ before being subjected to 25 cycles of denaturation at $94^{\circ} \mathrm{C}$ for $30 \mathrm{~s}$, annealing at $60^{\circ} \mathrm{C}$ for $30 \mathrm{~s}$, and polymerization at $72^{\circ} \mathrm{C}$ for $1 \mathrm{~min}$. The first reaction was performed on a conventional PCR machine (PC808, ASTEC Co. Ltd., Fukuoka, Japan). Two microliters of each resulting product was used as the template in the second snqPCR amplification performed using an ABI Prism 7000 Sequence Detection System (Life Technologies) using SYBR $^{\circledR}$ Green detection chemistry. Briefly, snqPCR amplification was performed in a $20-\mu \mathrm{L}$ final reaction volume containing $900 \mathrm{nmol} / \mathrm{L}$ of each primer used in the first RTPCR reaction (Table 2 ) and $1 \times \mathrm{SYBR}^{\circledR}$ Green PCR Master Mix (Life Technologies). The reaction mixture was preheated at $95^{\circ} \mathrm{C}$ for $10 \mathrm{~min}$, followed by 40 cycles of $95^{\circ} \mathrm{C}$ for $15 \mathrm{~s}$ and $60^{\circ} \mathrm{C}$ for $1 \mathrm{~min}$.

The initial concentration of CK6, CK7, CK14, CK18, TTF-1, and GAPDH mRNA were assessed using the above-described RT-PCR products as standard templates for further amplification with the same primers. The PCR reaction mixtures contained $1 \mu \mathrm{L}$ of cDNA, $1 \times$ AmpliTaq Gold $^{\circledR} 360$ PCR Master Mix (Life Technologies), $100 \mathrm{nM}$ of each primer, and double-distilled water to a final total 


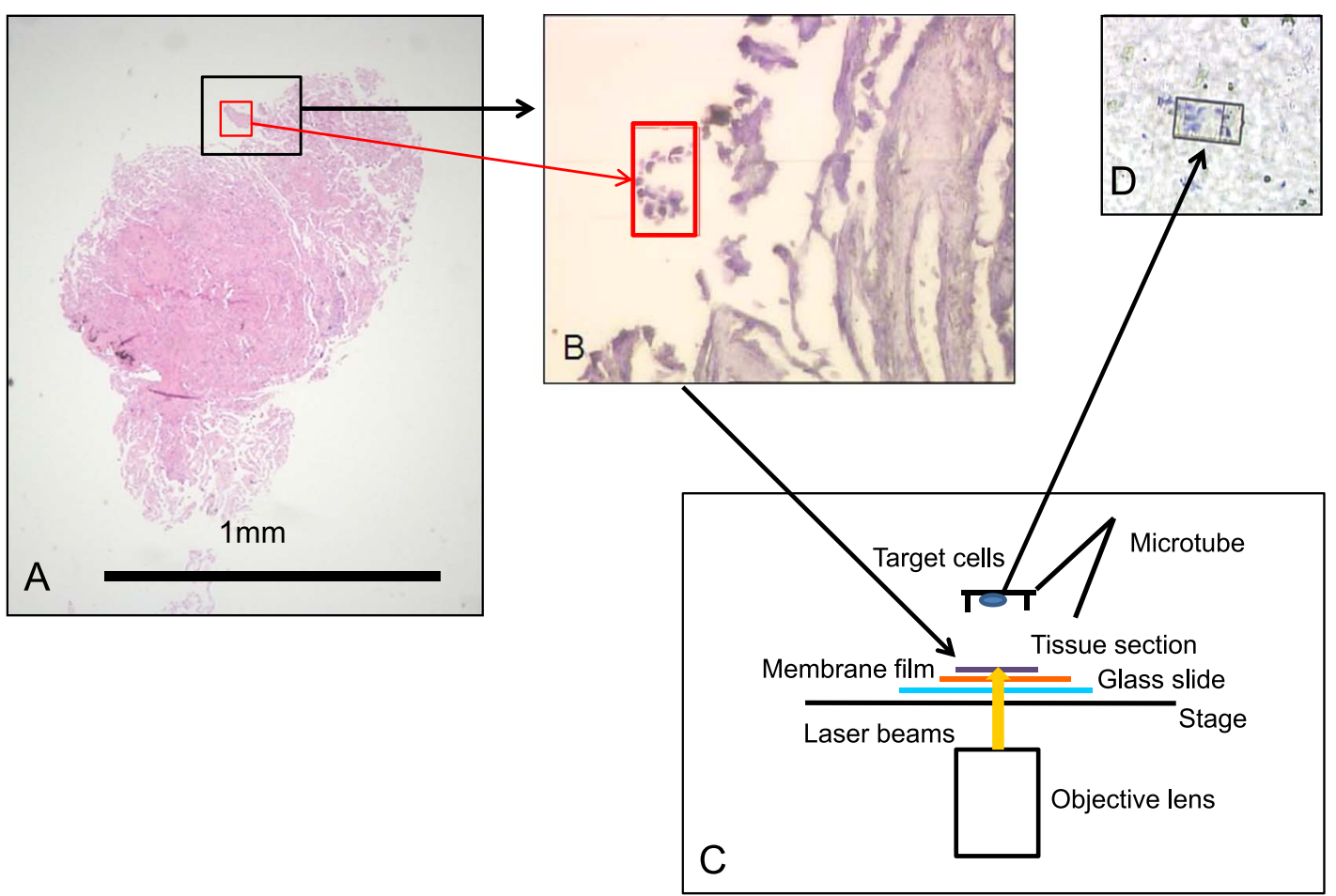

Fig. 2. Laser assisted microdissection (LMD) technique was used to assess the target tumor cells from lung biopsy sections. These sections were stained with hematoxylin and eosin (HE) and target tumor cells were identified under a light microscope $(\mathbf{A}, \times 100)$. In figure $\mathbf{A}$, tumor cells were found in only red square shape. The successive section of the same tissue block was stained with toluidine blue $(\mathbf{B}, \times 400)$ and the target tumor cells (B, red square shape) marked by software for LMD (PALM ${ }^{\circledR}$ RoboSoftware, Carl Zeiss Microscopy), under a light microscope without cover glass. Target tumor cells in Figure $\mathbf{B}$ were cut by laser beams and collected in Eppendorf's lid. Figure $\mathbf{C}$ shows the schematic illustration of the present LMD technique. Figure D shows a picture of Eppendorf's lid with the target tumor cells $(\times 100)$ caught inside.

Table 2. Primer sequences used in real time RT-PCR

\begin{tabular}{lllcr}
\hline Target & \multicolumn{1}{c}{ Forward primer } & Reverse primer & Tm $\left({ }^{\circ} \mathrm{C}\right)$ & Product size $(\mathrm{bp})$ \\
\hline CK5 & 5'-caaggttgatgcactgatgg-3' & 5'-tcagcgatgatgctatccag-3' & 60 & 150 \\
CK6 & 5'-gacctggtggaggacttcaa-3' & 5'-gtaggcagcatccacatcct-3' & 60 & 105 \\
CK7 & 5'-caggatgtggtggaggactt-3' & 5'-ttgctcatgtaggcagcatc-3' & 60 & 116 \\
CK14 & 5'-ggcctgctgagatcaaagac-3' & 5'-gtccactgtggctgtgagaa-3' & 60 & 83 \\
CK18 & 5'-gagatcgaggctctcaagga-3' & 5'-ctgagatttgggggcatcta-3' & 60 & 126 \\
CK19 & 5'-tttgagacggaacaggctct-3' & 5'-agctcttccttcaggcttc-3' & 60 & 128 \\
TTF-1 & 5'-ctccttgggaatgactggaa-3' & 5'-ccaagcaccacgatttttt-3' & 60 & 108 \\
GAPDH & 5'-ggaaggtgaaggtcggagtca-3' & 5'-gtcattgatggcaacaatatccact-3' & 60 & 101 \\
\hline
\end{tabular}

volume of $25 \mu \mathrm{L}$. The PCR reaction was carried out for 35 cycles at $95^{\circ} \mathrm{C}, 60^{\circ} \mathrm{C}$, and $72^{\circ} \mathrm{C}$, respectively, and the products were purified with Microcon 100 (Takara Bio Inc., Shiga, Japan). To assess the concentration of the PCR products, they were diluted with Tris-EDTA buffer from 1 to $1 \times 10^{8}$ copies $/ \mu \mathrm{L}$, and $1 \mu \mathrm{L}$ of each product was directly analyzed on Nanodrop 1000 (Thermo Fisher Scientific Inc.). We also examined whether the detection ranges of snqRT-PCR methods were improved. The quantity of target mRNA was standardized to the quantity of GAPDH mRNA. Snq RT-PCR products were visualized using $2 \%$ agar gel electrophoresis, followed by staining with $\mathrm{SYBR}^{\circledR}$ Green I to ensure product specificity.

\section{Immunohistochemistry}

Four-micrometer-thick sections were mounted onto silane-coated glass slides. After deparaffinization, the slides were prepared for antigen retrieval (Table 3). An automated staining system (Histostainer; Nichirei Bioscience, Tokyo, Japan) was used for the detection of CK5/6, CK7, CK14, CK18, CK19 and TTF-1 immunostaining using the following steps: (1) endogenous peroxidase blocking with 3\% hydrogen peroxide for $5 \mathrm{~min}$; (2) incubation with the primary antibodies (Table 3 ) for $30 \mathrm{~min}$ at room temperature; (3) washing with phosphate buffered saline (PBS); (4) incubation with the polymer second antibody (Simple stain Max PO Multi; Nichirei) for $30 \mathrm{~min}$ at room temper- 
Table 3. Antibodies for immunohistochemistry

\begin{tabular}{lclccc}
\hline Target & Company & Animal & Clone & Dilution ratio & Antigen retrieval \\
\hline CK5/6 & DAKO & Mouse & D5/16 B4 & $\times 100$ & A.C. $(\mathrm{pH} 9)$ \\
CK7 & DAKO & Mouse & OV-TL $12 / 30$ & $\times 100$ & A.C. $($ C.B. $)$ \\
CK14 & Novocastra & Mouse & LL002 & $\times 20$ & A.C. (C.B.) \\
CK18 & DAKO & Mouse & DC10 10 & $\times 50$ & A.C. $($ C.B.) \\
CK19 & DAKO & Mouse & RCK108 & $\times 80$ & A.C. (C.B.) \\
TTF-1 & DAKO & Mouse & $8 \mathrm{G} 7 \mathrm{G} 3 / 1$ & $\times 200$ & A.C. (C.B.) \\
\hline
\end{tabular}

A.C.: autoclave, C.B.: citrate buffer ( $\mathrm{pH} 6.0)$.

ature; (5) washing with PBS; (6) incubation with 3,3diaminobenzidine for $10 \mathrm{~min}$; (7) washing with PBS; and (8) staining with hematoxylin for $30 \mathrm{~s}$ and washing with PBS. Immunohistochemical expression was evaluated using the proportion score (PS). The PS describes the percentage of positively stained tumor cells $(0$, none; $1,<10 \% ; 2,10$ $50 \% ; 3,51-80 \% ; 4,>80 \%$ ).

\section{Statistical analysis}

Significant differences in the gene expression values between different histologies, clinical stages, and outcome of NSCLC were analyzed using the Mann-Whitney U test. The correlations between the immunohistochemical scores and the gene expression values were analyzed using a rank correlation test. These analyses were performed using SPSS $^{\circledR}$ Statistics version 20.0 (IBM Japan, Tokyo, Japan).

\section{Results}

\section{Improvement of the detection range using snqRT-PCR}

We attempted to measure the gene expression levels of CK6, CK7, CK14, CK18, and TTF-1 mRNA in small-mount lung biopsy samples to determine whether the histology subtype of NSCLC was AD or SQ. While it was difficult to measure the gene expression levels in microdissected FFPE lung biopsy specimens using conventional qRT-PCR, it was possible to measure these gene expression levels using the present method, which was performed by adding a pre-amplification PCR before the qRT-PCR assay. In this experiment, a standard sample of cDNA was obtained from FFPE lung biopsy samples that overexpressed CK6, CK7, CK14, CK18, and TTF-1, respectively. An SQ sample was used to measure the CK6 and CK14 mRNA expression levels, and an AD sample was used to measure the CK7, CK18, and TTF-1 mRNA expression levels. Using conventional qRT-PCR assays, the standard curves showed that over 104 copies of a target mRNA were measurable (Fig. 3A). SnqRT-PCR allowed the measurement of $10^{1}$ to $10^{7}$ copies of each target mRNA (Fig. 3A). The products of snqRT-PCR were confirmed to be the specific single bands observed in Figure 3B.

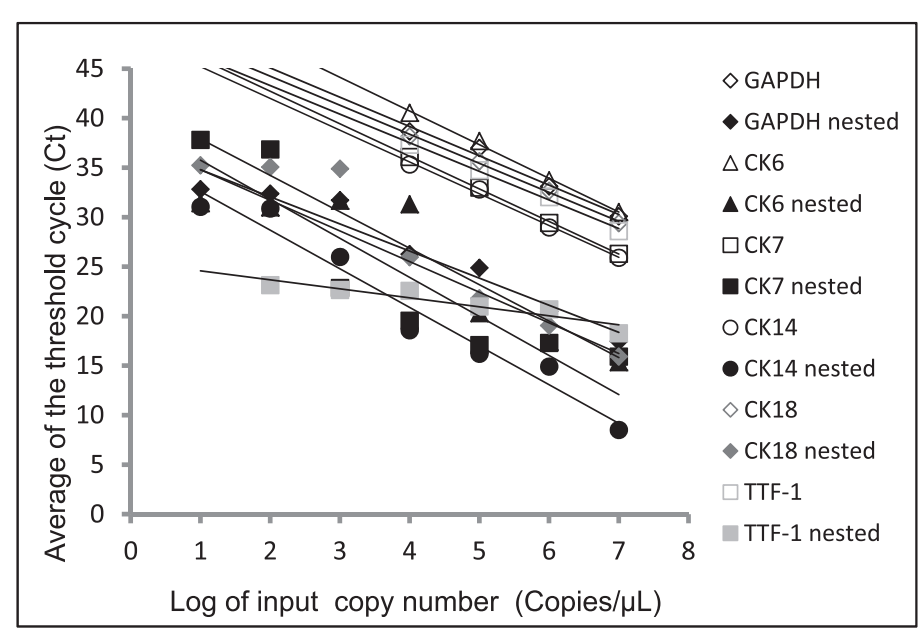

A

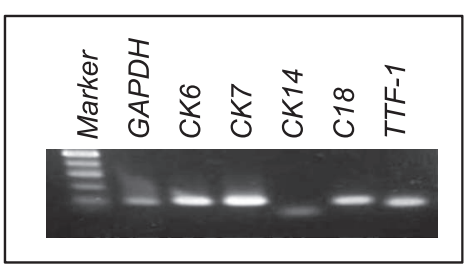

B

Fig. 3. (A) The logarithm of the input template copy number plotted versus the threshold cycle (Ct) from the same sample, as monitored by usual real-time RT-PCR (empty points) and nested real-time RT-PCR (solid points). The efficiency of GAPDH, CK6, CK7, CK14, CK18 and TTF-1 mRNA amplification are shown as regression lines. By usual real-time RT-PCR, the $\mathrm{R}^{2}$ of the regression formula were $0.979,0.996,0.999$, 0.994, 0.997, and 0.995, respectively. By snqRT-PCR, the $\mathrm{R}^{2}$ of the regression formula were $0.945,0.808,0.816,0.959,0.927$, and 0.881 , respectively. All points represent the mean of triplicate PCR amplifications. (B) The products of snqRT-PCR were visualized as specific single bands. 
Table 4. Number of patients with positive immunostaining and the immunohistochemical proportion scores (mean \pm SD) of each subtype of lung cancer

\begin{tabular}{ccccc}
\hline Target & Adenocarcinoma & Squamous cell carcinoma & Small cell carcinoma & Non-neoplastic lung tissue*1 \\
\hline CK5/6 & $5 / 33(15.2 \%)$ & $11 / 11(100 \%)$ & $0 / 8(0 \%)$ & $5 / 5(100 \%)$ \\
& $0.31 \pm 0.69$ & $* 3.00 \pm 0.00$ & 0.00 & $3.00 \pm 0.00$ \\
CK7 & $30 / 33(90.9 \%)$ & $2 / 11(18.2 \%)$ & $1 / 8(12.5 \%)$ & $5 / 5(100 \%)$ \\
& $* 2.44 \pm 0.98$ & $0.45 \pm 1.04$ & $0.13 \pm 0.35$ & $2.60 \pm 0.55$ \\
CK14 & $2 / 31(6.5 \%)$ & $11 / 11(100 \%)$ & $0 / 8(0 \%)$ & $0 / 5(0 \%)$ \\
& $0.17 \pm 0.46$ & $* 2.18 \pm 0.87$ & 0.00 & 0.00 \\
CK18 & $27 / 27(100 \%)$ & $6 / 12(50.0 \%)$ & $1 / 8(12.5 \%)$ & $5 / 5(100 \%)$ \\
& $* 2.81 \pm 0.57$ & $0.75 \pm 0.97$ & $0.13 \pm 0.35$ & $4.00 \pm 0.00$ \\
CK19 & $26 / 32(81.3 \%)$ & $6 / 12(50.0 \%)$ & $0 / 8(0 \%)$ & $5 / 5(100 \%)$ \\
& $1.57 \pm 1.09$ & $1.17 \pm 1.27$ & 0.00 & $0.55 \pm 1.40$ \\
TTF-1 & $22 / 33(66.7 \%)$ & $1 / 12(8.3 \%)$ & $4 / 8(50.0 \%)$ & $0 / 5(0 \%)$ \\
& $* 1.74 \pm 0.46$ & $0.08 \pm 0.29$ & $1.28 \pm 1.25$ & 0.00
\end{tabular}

*1: Non-neoplastic lung tissues were epithelium and tracheal gland.

*P $<0.05$, Mann-Whitney's $U$ test between adenocarcinoma and squamous cell carcinoma.

Proportion score determined by the ratio of positive staining cells: 0 , none; $1,<10 \% ; 2,10-50 \% ; 3,51-80 \% ; 4>80 \%$.
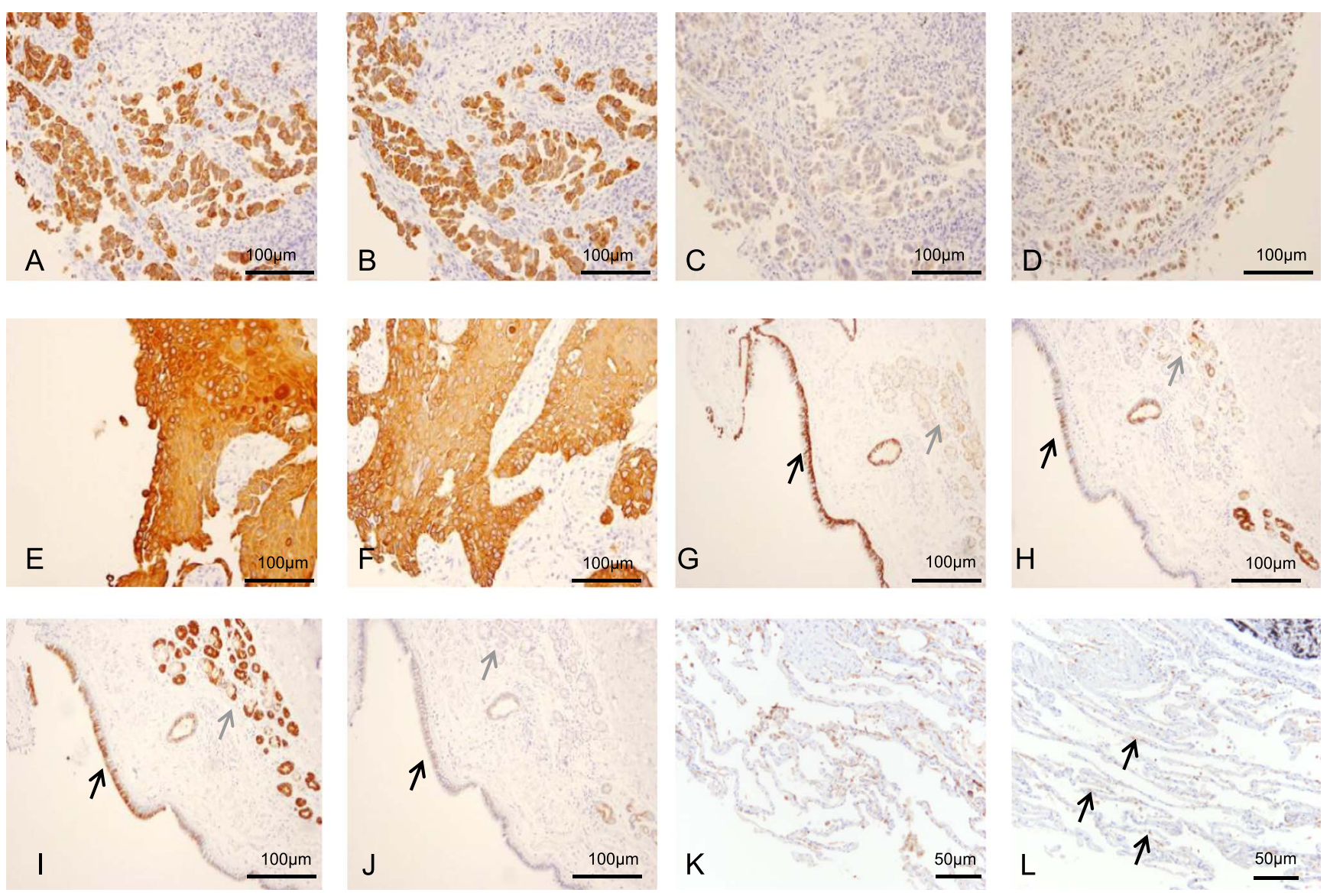

Fig. 4. Typical immunohistochemical staining patterns are shown. Cytokeratin 7 was overexpressed in cytoplasm of ADs (A) and nonneoplastic tissues ( $\mathbf{H}$ and $\mathbf{K}$, both black and gray arrows). Cytokeratin 18 was overexpressed in cytoplasm of ADs (B) and non-neoplastic tissues (I and $\mathbf{L}$, both black and gray arrows). Cytokeratin 19 was low expressed in cytoplasm of ADs (C) and non-neoplastic airway epithelial cells $(\mathbf{J}$, black arrow) and tracheal glands ( $\mathbf{J}$, gray arrow). Thyroid transcription factor-1 was overexpressed in nuclei of ADs (D). Cytokeratin (CK) 5/6 was overexpressed in the cytoplasm of squamous cell carcinoma (SQ) cells (E) and in non-neoplastic airway epithelial cells (G, black arrow) and low expressed in non-neoplastic tracheal glands (G, gray arrow). Cytokeratin 14 was overexpressed in cytoplasm of SQs (F). 
Table 5. Correlation between immunohistochemical proportion score and gene expression

\begin{tabular}{|c|c|c|c|c|c|c|}
\hline \multirow{2}{*}{ Target } & \multicolumn{4}{|c|}{ IHC score (PS) } & \multirow{2}{*}{$\begin{array}{l}\text { Correlation } \\
\text { coefficient }\end{array}$} & \multirow{2}{*}{$\mathrm{P}$ value } \\
\hline & 1 & 2 & 3 & 4 & & \\
\hline CK5/6 & $0.03 \pm 0.02$ & No sample & $0.04 \pm 0.00$ & $3.24 \pm 5.43$ & 0.43 & $0.010^{*}$ \\
\hline CK7 & $0.01 \pm 0.01$ & $0.10 \pm 0.27$ & $0.10 \pm 0.22$ & $11.16 \pm 31.6$ & 0.36 & $0.0015^{*}$ \\
\hline CK14 & $0.03 \pm 0.08$ & $0.70 \pm 1.55$ & $13.4 \pm 20.7$ & $30.13 \pm 45.9$ & 0.48 & $<0.001 * *$ \\
\hline CK18 & $0.05 \pm 0.06$ & $0.11 \pm 0.00$ & $0.24 \pm 0.13$ & $5.52 \pm 15.7$ & 0.52 & $<0.001^{* *}$ \\
\hline TTF-1 & $1.58 \pm 1.32$ & No sample & $45.3 \pm 76.8$ & $339.5 \pm 470.8$ & 0.26 & 0.07 \\
\hline
\end{tabular}

$* \mathrm{P}<0.05, * * \mathrm{P}<0.001$.

Proportion score determined by the ratio of positive staining cells: 0 , none; $1,<10 \% ; 2,10-50 \% ; 3,51-80 \% ; 4,>80 \%$.

\section{Immunohistochemical findings}

We also examined the protein overexpression of CK5/6, CK7, CK14, CK18, CK19, and TTF-1 using immunohistochemistry and compared the results with the mRNA expression levels of each target gene, as measured using snqRT-PCR. The number of cases with positive staining and the mean of the PS are shown in Table 4. In ADs, CK7, CK18, and TTF-1 positivity was observed in $90.9 \%, 100 \%$, and $66.7 \%$ of the cases, respectively. The PS of CK7, CK18, and TTF-1 positivity were significantly higher in ADs than in SQs $(\mathrm{P}<0.05)$. In SQs, the number of cases with positive staining for both CK5/6 and CK14 was found to be $100 \%$, and the PSs of CK5/6 and CK14 were significantly higher than that observed in ADs $(\mathrm{P}<0.05)$. In SMs, positive immunostaining was observed for CK7, CK18, and TTF- 1 in $12.5 \%, 12.5 \%$, and $50.0 \%$ of the cases, respectively. Although the same positive staining panel was observed in ADs, the intensity was much weaker than that in ADs. In non-neoplastic tissues, CK5/6, CK7, CK18 and CK19 were expressed in airway epithelial cells and in tracheal gland cells. Alveolar epithelial exhibited CK7 and CK18 positivity. A typical immunostaining pattern was shown in Figure 4. In ADs, CK7 and CK18 were overexpressed in cytoplasm (Fig. $4 \mathrm{~A}$ and $\mathrm{B}$, respectively). CK19 was expressed in the cytoplasm of AD (Fig. 4C), and TTF-1 was expressed in the nuclei of AD (Fig. 4D). In SQs, CK5/6 and CK14 were overexpressed in the cytoplasm (Fig. 4E and F, respectively). In non-neoplastic tissues, CK5/6 and CK18 were overexpressed in the cytoplasm of airway epithelial cells (Fig. 4G and I, black arrow), and CK7 and CK19 were weakly expressed in airway epithelial cells (Fig. 4H and J, black arrow). Both CK7 and CK18 were expressed in the cytoplasm of tracheal gland cells (Fig. 4H and I, gray arrow). On the other hand, CK5/6 and CK19 were weakly expressed in the cytoplasm of tracheal gland cells (Fig. 4G and J, gray arrow). Cytokeratin

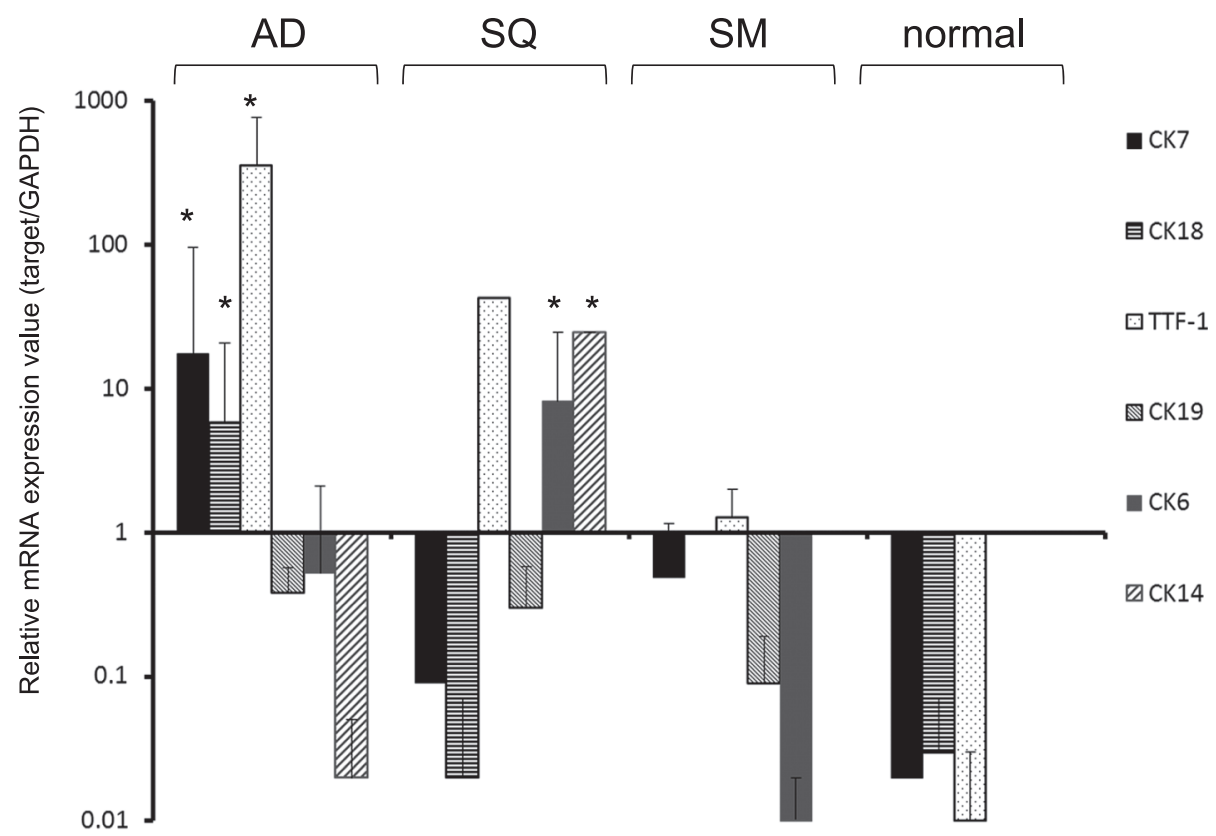

Fig. 5. Levels of mRNA expression of the target genes are shown in adenocarcinoma (AD), squamous cell carcinoma (SQ), small cell carcinoma $(\mathrm{SM})$, and normal samples (mean $\pm \mathrm{SD}$ ). In ADs, CK7, CK18, and TTF-1 mRNA expression was significantly higher $(\mathrm{P}<0.05)$ than in other carcinoma and normal samples, while in SQs, CK6 and CK14 mRNA expression was significantly higher $(\mathrm{P}<0.05)$ than in other carcinoma and normal samples. The expression of all target mRNA were low in normal samples. 
7 and CK18 were also expressed in the cytoplasm of nonneoplastic alveolar epithelial cells (Fig. 4K and L, black arrow). The PSs of CK5/6, CK7, CK14, and CK18 are significantly correlated with the mRNA expression value of each target gene $(\mathrm{P}=0.01,0.0015,0.0002$, and $\mathrm{P}<0.001$, respectively; Table 5).

\section{$A D$ and $S Q$ overexpress the $M R N A$ of different subtypes of keratin}

The mRNA expression levels of CK6, CK7, CK14, CK18, CK19, and TTF-1 in microdissected tumor cells were measured in FFPE lung biopsy specimens using a snqRT-PCR technique (Fig. 5). The expression of CK7, CK18, and TTF-1 mRNA was significantly higher in ADs than in SQs, SMs, and normal tissues. SQs expressed significantly higher levels of CK6 and CK14 mRNA than others. Although positive immunohistochemical expression of CK $5 / 6$, CK 7, and CK 18 was observed in normal tissues, the mRNA expression levels were lower than those in carcinoma samples.

\section{CK $m R N A$ expression and NSCLC malignancy}

In this study, a correlation between the CK mRNA expression level and the clinical stage, which is an important risk factor for predicting the prognosis, were analyzed. In ADs, the CK7 and CK18 mRNA expression levels in early-stage cases were lower than those in advanced cases. However, the mRNA expression levels of CK7 and CK18 were not correlated with the clinical stage (Fig. 6A). On the other hand, the mRNA expression levels of CK6 and CK14 were found to be significantly higher in SQs at a late clinical stage than at earlier clinical stages $(\mathrm{P}=0.02, \mathrm{P}=0.04$, respectively; Fig. 6B). The correlations among the $\mathrm{CK}$
mRNA expression level, clinical stage, and prognosis in patients with prognostic information were investigated (Tables 6, 7). In ADs, the CK18 mRNA expression level was not different between stage III and stage IV but was significantly higher among the cases that died than among the cases that survived, particularly for stage III (Table 6; $\mathrm{P}=0.02$ ). The correlation between the clinical stage and the prognosis was not clear in the present cases. The CK7 mRNA expression level was correlated with neither the clinical stage nor the prognosis. In SQs, the CK6 mRNA expression level was significantly correlated with the prognosis in stage III and stage IV cases (Table 7; $\mathrm{P}=0.02$ ). The correlation between the clinical stage and the prognosis was not clear in the present cases. The CK14 mRNA expression level was correlated with neither the clinical stage nor the prognosis.

\section{Discussion}

The emergence of treatments for NSCLC with different efficacies and toxicities for different subtypes of this disease has highlighted the importance of specific pathological NSCLC subtyping [18]. As most advanced NSCLCs are inoperable, the pathological diagnosis must be made using small-mount biopsy specimens, which is often difficult because of the low number of tumor cells present in such samples.

In this study, the mRNA expression levels of a variety of keratin subtypes and TTF-1, which are known immunohistochemical markers used for subtyping NSCLC, were measured in lung biopsy specimens using LMD and snqRTPCR methods. Our results demonstrated that these techniques may potentially be used to subtype advanced

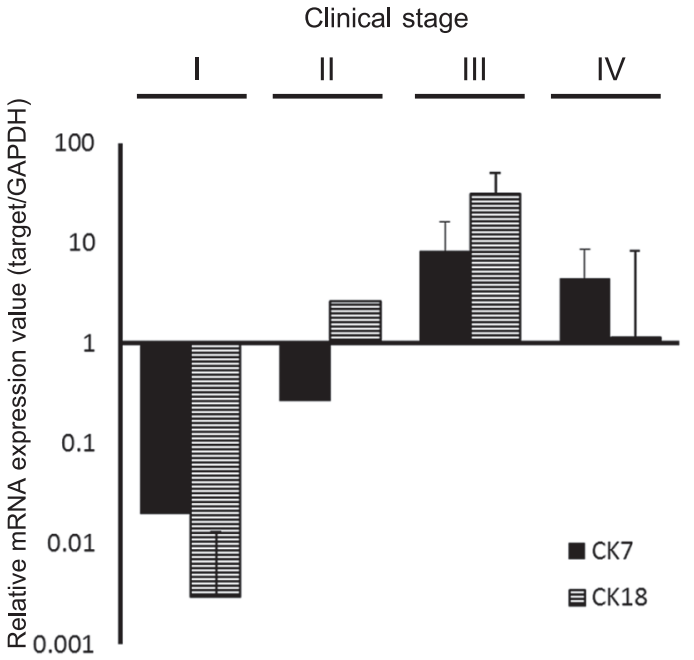

A: AD

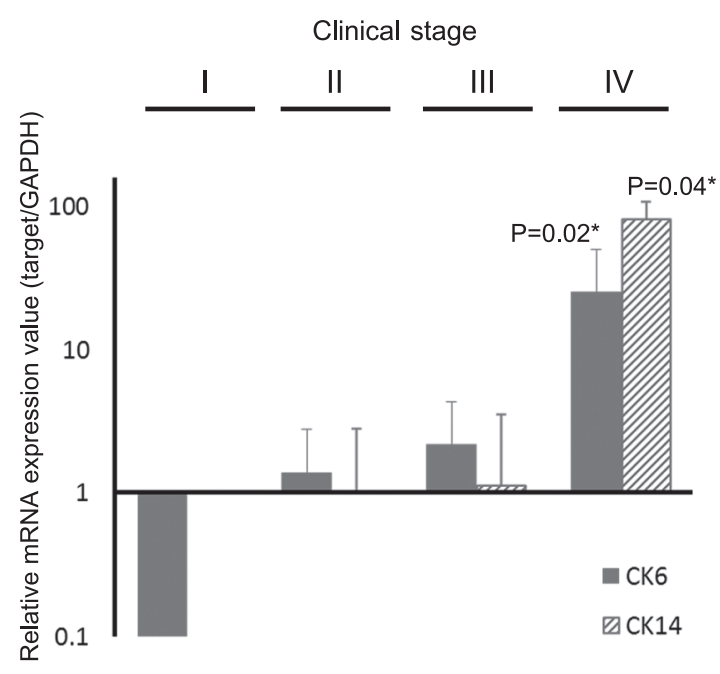

$B: S Q$

Fig. 6. Correlation between mRNA expression value and clinical stage in lung squamous cell carcinoma (SQ: A) and in lung adenocarcinoma (AD: B). In SQ, the expression of CK6 and CK14 mRNA was significantly higher in the stage IV samples than in the lower stage samples $(\mathrm{P}=0.02,0.04$, respectively). While CK7 and CK18 mRNA expression were lower in the stage I AD samples than in the samples of other stages, no correlation between mRNA expression and clinical stage was found in AD. 
NSCLC and to predict patient prognosis from small-mount and FFPE biopsy samples. AD is a group of tumors with diverse morphology, composed of lepidic, acinar, papillary, solid and micropapillary growth patterns, and these mor- phological assessments are quite important for predicting the prognosis of operable NSCLC. In this study, the correlation between the cytokeratin mRNA expression level and the detailed morphology pattern was not clear. In patients

Table 6. Correlation between $C K 7$ and CK18 mRNA expression level and prognosis in lung adenocarcinoma

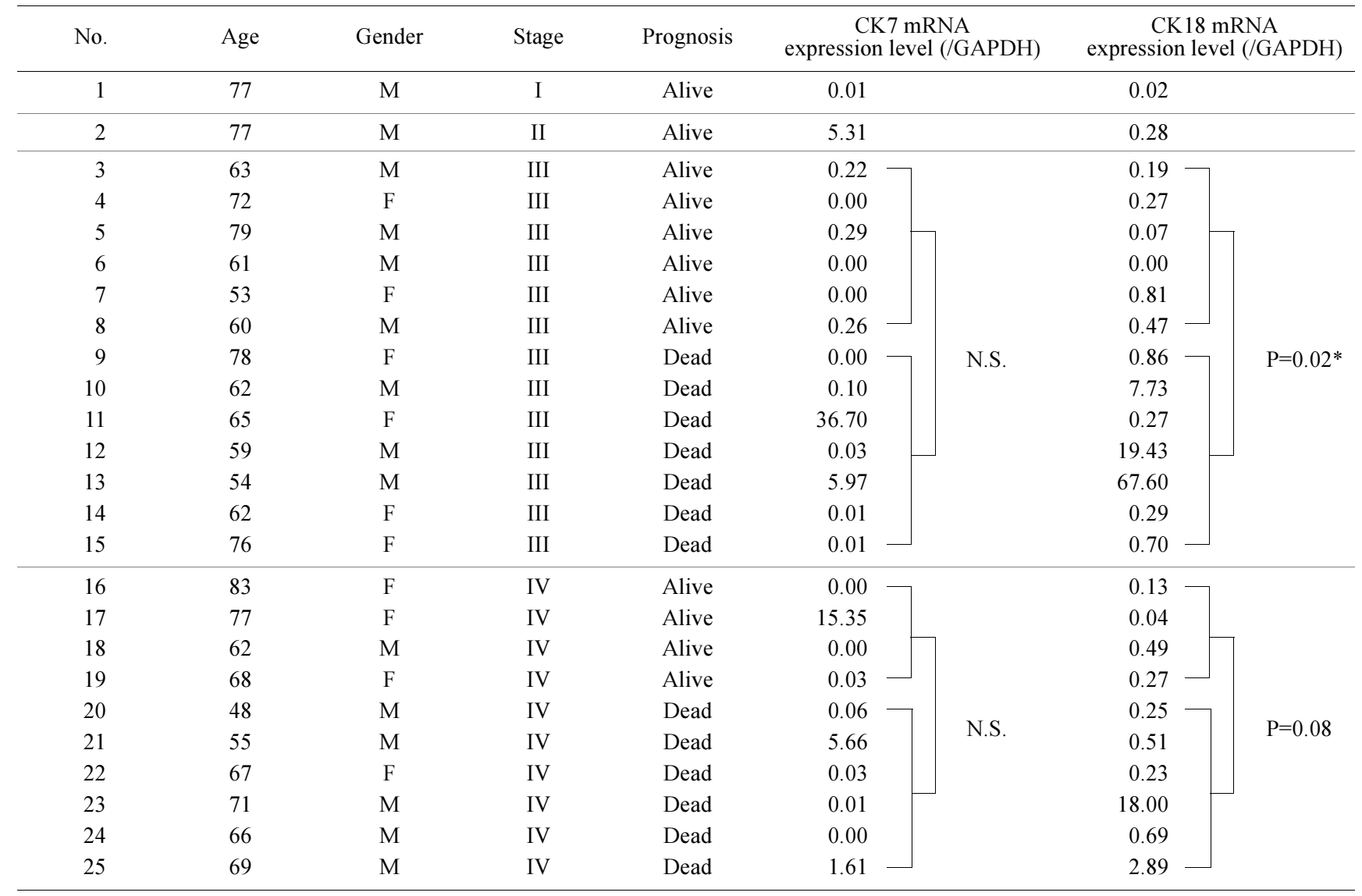

$* \mathrm{P}<0.05$, N.S.: no significant.

Table 7. Correlation between CK6 and CK14 mRNA expression level and prognosis in lung squamous cell carcinoma

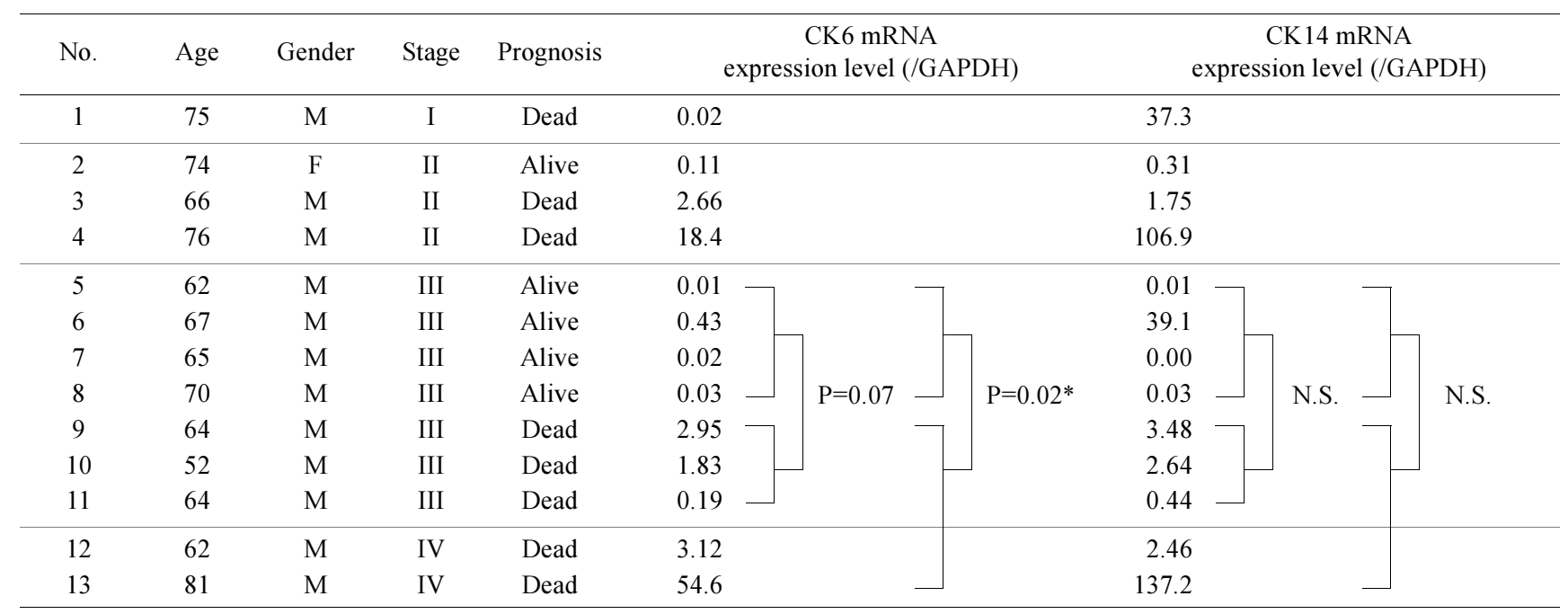

$* \mathrm{P}<0.05$, N.S.: no significant. 
with inoperable advanced NSCLC, however, rapid histological subtyping was required, rather than a morphological analysis, to decide the indications for drug treatment.

While it has been demonstrated in many laboratories that it is possible to use a variety of quantitative molecular methods in FFPE archival samples [2, 9, 10, 12, 14, 27, 29, $31,32,34]$, mRNA analysis tends to be difficult because of RNA fragmentation as a result of formalin fixation [6]. We previously reported that LMD techniques are useful for mRNA analyses in heterogenetic tissue samples [20, 2325]. In this study, we applied the use of snRT-PCR methods to qRT-PCR in an attempt to improve the success of quantitative mRNA analysis using small-mount microdissected FFPE samples. Previously, snqPCR and snqRTPCR techniques have been described with regard to methylation-specific DNA analyses in small-mount clinical samples [16] and the detection of microbial DNA and human immunodeficiency virus type 1 RNA from plasma or oral swabs $[26,30]$. The analysis of mRNA expression levels from FFPE clinical samples using snqRT-PCR has not been previously reported. Our results also show a good correlation between keratin mRNA expression levels, which were measured using snqRT-PCR, and the immunohistochemical proportion score of these proteins. Therefore, the sensitive quantitation of mRNA expression in small samples that are not amenable to sufficient immunohistochemical analysis was considered to be applicable for predicting immunohistochemical protein expression. The sensitivity of qRT-PCR was increased by the present snqRT-PCR method. This technique is not absolutely suitable for the detection of minimal differences, but may be useful for analyzing the characteristic expression of cancer cells even from small-mount FFPE biopsy samples, since cancer cells often show quite different molecular changes from non-neoplastic cells.

Furthermore, our examination of the mRNA expression of specific keratin subtypes in AD and SQ samples suggests that this technique not only has potential use in histology subtyping, but also in predicting patient prognosis. Indeed, the mRNA expression of keratin subtypes was quite different between ADs and SQs, particularly with regard to CK18 mRNA overexpression in AD and CK6 mRNA overexpression in SQ, and the mRNA overexpression of both CK18 and CK6 was found to be correlated with a poor prognosis. Although clinical stage is one of the most important risk factors for predicting a poor prognosis, the CK mRNA expression level was quite variable in each of the stage III and stage IV groups. Indeed, in the present study, the CK18 mRNA expression level in AD and the CK6 mRNA expression level in SQ were significantly different between the patients that died and the patients that survived, particularly among advanced-stage patients. As many of the present patients had an advanced stage, however, the correlation between CK mRNA expression and prognosis in early-stage patients could not be clarified. But even in early-stage NSCLC cases, the CK mRNA expression level was thought to be correlated with a poor prognosis. Our study disclosed a tendency toward resistance against chemotherapy in cases with a high $\mathrm{CK}$ mRNA expression level (data not shown). CK18 is a low molecular weight keratin and is largely expressed in all simple epithelia, ductal epithelia, pseudostratified epithelia, and carcinoma cells arising from simple epithelia, except for basal cell carcinoma and squamous cell carcinoma [5]. Furthermore, CK18 is localized in apical areas of the rabbit duodenum and columnar cells, and the involvement of CK18 in the apex and peripheral networks have been suggested [11]. CK18 has been reported to function in intercellular signaling as a growth factor in conjunction with CK8 [38] and has been used as a serum biomarker for carcinoma. The plasma levels of total CK18 were found to be higher in the NSCLC group, compared with healthy and benign lung disease groups [7]. These results suggested that CK18 protein is more highly expressed in various carcinoma cells and is correlated with tumor progression $[17,19$, 33]. Furthermore, a correlation between the overexpression of membrane protein and glycoprotein and the appearance of resistance to platinum and the reduced intracellular uptake of platinum has been reported [1, 13]. The overexpression of CK18 in AD may induce the activation of a cytoskeletal signaling network involving phosphorylation, glycosylation and transglutamination, thereby inhibiting the intercellular uptake of anticancer drugs. The response to therapy is a risk factor that determines patient prognosis. Therefore, further study of tumor cells with high CK mRNA expression levels is now underway to study the potential adverse effects of anticancer drug resistance.

Cytokeratin 7 has sometimes been used as a marker of $\mathrm{AD}$, while $\mathrm{CK} 5 / 6$ has been used as a marker for SQ in NSCLC diagnosis. Our results demonstrate that, of the CK subtypes, CK18 is preferable to CK7 for the discrimination of histology and the prediction of the prognosis of patients with AD. Although CK19 has been used for the detection of other carcinomas, the levels were low in lung ADs. Our results also show that CK6 overexpression occurs not only in basal cells, but also in SQ cells, especially in patients with a poor prognosis. In addition to differences in morphology, the biology of SQs may also be quite different from ADs, which may impact NSCLC therapeutic performance. The function of CK subtype overexpression in the induction of tumor progression or resistance to treatments, therefore, needs to be clarified. Finally, various analyses of small and FFPE clinical samples will become more necessary for clarifying the correlation among morphology, molecular features, therapeutic response and clinical outcome in not only patients with advanced NSCLC, but also patients with other inoperable diseases. Our findings support the improvement of quantitative mRNA analysis for small, heterogenetic and FFPE biopsy specimens.

\section{Acknowledgments}

We wish to thank the staff members of the Department of Pathology, Department of Respiratory Medicine, and 
Nihon University Itabashi Hospital, for their assistance.

This work was supported in part by Nihon University School of Medicine Hagiwara Fund Research Grant (2010), by a grant from the Strategic Research Base Development Program for Private Universities subsidized by MEXT (2010), and by Grants-in-Aid from the National Cancer Research and Development Fund (23-A-35).

\section{References}

1. Bernal, S. D., Speak, J. A., Boeheim, K., Dreyfuss, A. I., Wright, J. E., Teicher, B. A., Rosowsky, A., Tsao, S. W. and Wong, Y. C. (1990) Reduced membrane protein associated with resistance of human squamous carcinoma cells to methotrexate and cisplatinum. Mol. Cell. Biochem. 95; 61-70.

2. Burgemeister, R. (2011) Nucleic acids extraction from laser microdissected FFPE tissue sections. Methods Mol. Biol. 724; $117-129$

3. Burnett, R. A., Swanson, J., Beck, S. R., Howatson, F. D., Lee, A. M., Lessells, K. M., McLaren, S., Ogston, A. J., Robertson, J. G., Simpson, G. D. and Smith, G. D. (1994) Observer variability in histopathological reporting of malignant bronchial biopsy specimens. J. Clin. Pathol. 47; 711-713.

4. Cataluña, J. J., Perpiñá, M., Greses, J. V., Calvo, V., Padilla, J. D. and París, F. (1996) Cell type accuracy of bronchial biopsy specimens in primary lung cancer. Chest 109; 1199-1203.

5. Chu, P. G. and Weiss, L. M. (2002) Keratin expression in human tissues and neoplasms. Histopathology 40; 403-439.

6. Cronin, M., Pho, M., Dutta, D., Stephans, J. C., Shak, S., Kiefer, M. C., Esteban, J. M. and Baker, J. B. (2004) Measurement of gene expression in archival paraffin-embedded tissues. Am. J. Pathol. 164; 35-42.

7. De Petris, L., Branden, E., Herrmann, R., Sanchez, B. C., Koyi, H., Linderholm, B., Lewensohn, R., Linder, S. and Lehtio, J. (2011) Diagnostic and prognostic role of plasma levels of two forms of cytokeratin 18 in patients with non-small-cell lung cancer. Eur. J. Cancer 47; 131-137.

8. Edwards, S. L., Roberts, C., McKean, M. E., Cockburn, J. S., Jeffrey, R. R. and Kerr, K. M. (2000) Preoperative histological classification of primary lung cancer: accuracy of diagnosis and use of the non-small cell category. J. Clin. Pathol. 53; 537-540.

9. Finke, J., Fritzen, R., Temes, P., Lange, W. and Dolken, G. (1993) An improved strategy and a useful housekeeping gene for RNA analysis from formalin-fixed, paraffin-embedded tissues by PCR. Biotechniques 14; 448-453.

10. Godfrey, T. E., Kim, S. H., Chavira, M., Ruff, D. W., Warren, R. S., Gray, J. W. and Jensen, R. H. (2000) Quantitative mRNA expression analysis from formalin-fixed, paraffin-embedded tissues using $5^{\prime}$ nuclease quantitative reverse transcription-polymerase chain reaction. J. Mol. Diagn. 2; 84-91.

11. Iwatsuki, H. and Suda, M. (2010) Seven kinds of intermediate filament networks in the cytoplasm of polarized cells: structure and function. Acta Histochem. Cytochem. 43; 19-31.

12. Jacobson, T. A., Lundahl, J., Mellstedt, H. and Moshfegh, A. (2011) Gene expression analysis using long-term preserved formalin-fixed and paraffin-embedded tissue of non-small cell lung cancer. Int. J. Oncol. 38; 1075-1081.

13. Kawai, K., Kamatani, N., Georges, E. and Ling, V. (1990) Identification of a membrane glycoprotein overexpressed in murine lymphoma sublines resistant to cis-diamminedichloroplatinum (II). J. Biol. Chem. 265; 13137-13142.

14. Klopfleisch, R., Weiss, A. T. and Gruber, A. D. (2011) Excavation of a buried treasure-DNA, mRNA, miRNA and protein analysis in formalin fixed, paraffin embedded tissues. Histol. Histopathol. 26; 797-810.
15. Komatsu, K., Nakanishi, Y., Seki, T., Fuchinoue, F., Amano, S., Komatsu, A., Sugitani, M. and Nemoto, N. (2008) Application of liquid-based preparation to fine needle aspiration cytology in breast cancer. Acta Cytol. 52; 591-596.

16. Lee, J. S., Fackler, M. J., Lee, J. H., Choi, C., Park, M. H., Yoon, J. H., Zhang, Z. and Sukumar, S. (2010) Basal-like breast cancer displays distinct patterns of promoter methylation. Cancer Biol. Ther. 9; 1017-1024.

17. Linder, S., Olofsson, M. H., Herrmann, R. and Ulukaya, E. (2010) Utilization of cytokeratin-based biomarkers for pharmacodynamic studies. Expert Rev. Mol. Diagn. 10; 353-359.

18. Loo, P. S., Thomas, S. C., Nicolson, M. C., Fyfe, M. N. and Kerr, K. M. (2010) Subtyping of undifferentiated non-small cell carcinomas in bronchial biopsy specimens. J. Thorac. Oncol. 5; 442-447.

19. Messai, Y., Noman, M. Z., Derouiche, A., Kourda, N., Akalay, I., Hasmim, M., Stasik, I., Ben Jilani, S., Chebil, M., Caignard, A., Azzarone, B., Gati, A., Ben Ammar Elgaaied, A. and Chouaib, S. (2010) Cytokeratin 18 expression pattern correlates with renal cell carcinoma progression: relationship with Snail. Int. J. Oncol. $36 ; 1145-1154$.

20. Mizutani, G., Nakanishi, Y., Watanabe, N., Honma, T., Obana, Y., Seki, T., Ohni, S. and Nemoto, N. (2012) Expression of somatostatin receptor (SSTR) subtypes (SSTR-1, 2A, 3, 4 and 5) in neuroendocrine tumors using real-time RT-PCR method and immunohistochemistry. Acta Histochem. Cytochem. 45; 167-176.

21. Moll, R., Divo, M. and Langbein, L. (2008) The human keratins: biology and pathology. Histochem. Cell Biol. 129; 705-733.

22. Mukhopadhyay, S. and Katzenstein, A. L. A. (2011) Subclassification of non-small cell lung carcinomas lacking morphologic differentiation on biopsy specimens: utility of an immunohistochemical panel containing TTF-1, napsin A, p63, and CK5/6. Am. J. Surg. Pathol. 35; 15-25.

23. Nakanishi, Y., Mizutani, G., Sano, M., Oinuma, T. and Nemoto, N. (2004) Comparison of HER2 mRNA amplification with immunohistochemistry in human breast cancer using laser assisted microdissection technique. Acta Histochem. Cytochem. 37; 73-79.

24. Nakanishi, Y., Oinuma, T., Sano, M., Fuchinoue, F., Komatsu, K., Seki, T., Obana, Y., Tabata, M., Kikuchi, K., Shimamura, M., Ohmori, K. and Nemoto, N. (2006) Coexpression of an unusual form of the EWS-WT1 fusion transcript and interleukin 2/15 receptor beta mRNA in a desmoplastic small round cell tumour. J. Clin. Pathol. 59; 1108-1110.

25. Ohno, C., Nakanishi, Y., Honma, T., Henmi, A., Sugitani, M., Kanai, Y. and Nemoto, N. (2009) Significance of system L amino acid transporter 1 (LAT-1) and 4F2 heavy chain (4F2hc) expression in human developing intestines. Acta Histochem. Cytochem. $42 ; 73-81$

26. Pasternak, A. O., Adema, K. W., Bakker, M., Jurriaans, S., Berkhout, B., Cornelissen, M. and Lukashov, V. V. (2008) Highly sensitive methods based on seminested real-time reverse transcription-PCR for quantitation of human immunodeficiency virus type 1 unspliced and multiply spliced RNA and proviral DNA. J. Clin. Microbiol. 46; 2206-2211.

27. Reichmuth, C., Markus, M. A., Hillemmans, M., Atkinson, M. J., Unni, K. K., Saretzki, G. and Hofler, H. (1996) The diagnostic potential of the chromosome translocation $\mathrm{t}(2 ; 13)$ in rhabdomyosarcoma: a PCR study of fresh frozen and paraffin-embedded tumor samples. J. Pathol. 180; 50-57.

28. Rossi, G., Pelosi, G., Graziano, P., Barbareschi, M. and Papotti, M. (2009) A reevaluation of the clinical significance of histological subtyping of non-small-cell lung carcinoma: diagnostic algorithms in the era of personalized treatments. Int. J. Surg. Pathol. 17; 206-218.

29. Rupp, G. M. and Locker, J. (1988) Purification and analysis of RNA from paraffin embedded tissues. Biotechniques 6; 56-60 
30. Saini, R., Santhanam, J., Othman, N. H., Saini, D. and Tang, T. H (2009) Single-tube seminested PCR assay for detecting human papillomavirus in clinical samples. Open Microbiol. J. 3; 106112.

31. Sheils, O. M. and Sweeney, E. C. (1999) TSH receptor status of thyroid neoplasms-TaqMan RT-PCR analysis of archival material. J. Pathol. 188; 87-92.

32. Steinau, M., Patel, S. S. and Unger, E. R. (2011) Efficient DNA extraction for HPV genotyping in formalin-fixed, paraffinembedded tissues. J. Mol. Diagn. 13; 377-381.

33. Sullivan, B. T., Cherry, J. A., Sakamoto, H., Henkes, L. E., Townson, D. H. and Rueda, B. R. (2010) Cytokeratin 18 expression inhibits cytokine-induced death of cervical cancer cells. Int. J. Gynecol. Cancer 20; 1474-1481.

34. Tangrea, M. A., Mukherjee, S., Gao, B., Markey, S. P., Du, Q., Armani, M., Kreitman, M. S., Rosenberg, A. M., Wallis, B. S., Eberle, F. C., Duncan, F. C., Hanson, J. C., Chuaqui, R. F., Rodriguez-Canales, J. and Emmert-Buck, M. R. (2011) Effect of immunohistochemistry on molecular analysis of tissue samples: implications for microdissection technologies. J. Histochem. Cytochem. 59; 591-600.

35. Terry, J., Leung, S., Laskin, J., Leslis, K. O., Gown, A. M. and
Ionescu, D. N. (2010) Optimal immunohistochemical markers for distinguishing lung adenocarcinomas from squamous cell carcinomas in small tumor samples. Am. J. Surg. Pathol. 34; 1805-1811.

36. Travis, W. D. and Rekhtman, N. (2011) Pathological diagnosis and classification of lung cancer in small biopsies and cytology: strategic management of tissue for molecular testing. Semin. Respir. Crit. Care Med. 32; 22-31.

37. Waschke, J. (2008) The desmosome and pemphigus. Histochem. Cell Biol. 130; 21-54.

38. Yamashiro, Y., Takei, K., Umikawa, M., Asato, T., Oshiro, M., Uechi, Y., Ishikawa, T., Taira, K., Uezato, H. and Kariya, K. (2010) Ectopic coexpression of keratin 8 and 18 promotes invasion of transformed keratinocytes and is induced in patients with cutaneous squamous cell carcinoma. Biochem. Biophys. Res. Commun. 399; 365-372.

This is an open access article distributed under the Creative Commons Attribution License, which permits unrestricted use, distribution, and reproduction in any medium, provided the original work is properly cited. 